\title{
Growth and photosynthetic reactions of different species of wheat seedlings under drought and salt stress
}

\author{
NINA TERLETSKAYA ${ }^{1}$ \\ NATALIA ZOBOVA ${ }^{2}$ \\ VALENTINA STUPKO ${ }^{2}$ \\ ELENA SHUYSKAYA ${ }^{3}$ \\ ${ }^{1}$ Institute of Plant Biology and Biotechnology \\ of Science Committee of the Ministry of Education \\ and Science of the Republic of Kazakhstan \\ (IPBB KH MES), 050040, Timiryazev str., 45, Almaty, \\ Kazakhstan, e-mail: teni02@mail.ru \\ ${ }^{2}$ Federal State Institution of Science \\ „Krasnoyarsk Research Institute of Agriculture“, \\ Svobodnyi av., 66, Krasnoyarsk, Russia, \\ e-mail:zobovnat@mail.ru \\ ${ }^{3}$ K.A. Timiryazev Institute of Plant Physiology Russian \\ Academy of Science, Botanical str., 55, Moscow, \\ Russia, e-mail: evshuya@mail.ru

\section{Correspondence:} \\ Nina Terletskaya \\ E-mail: teni02@mail.ru
}

Keywords: Triticum species, drought, salt stress, chlorophyll, photosynthesis.

Received July 7, 2016.

Revised November 22, 2016.

Accepted November 25, 2016.

\begin{abstract}
Background and Purpose: Comprehension of how the different representatives of the tribe Triticeae tolerate to abiotic stresses is essential for the discovery of new tolerance sources and therefore for the development of breeding and genetic researches in stress tolerance improvement of such important crops as wheat. The aim of the study was to identify growth reactions and associated changes in the photosynthetic apparatus of different wheat species in response to drought and salt stress.
\end{abstract}

Materials and Methods The changes of seedlings growth parameters of 6 wheat species under the influence of the drought and salt stress under laboratory conditions were investigated. Content chlorophyll $a$ and $b$ was determined. The fluorescence quantum yield of photosystem II and electron transport rate through the photosystem II (ETR) was studied.

Results: The relationship between changes in growth activity of seedlings of different wheat species under abiotic stresses and the work of the photosynthetic apparatus was showed. The tetraploid species T. dicoccum Schuebl. and $\mathrm{T}$. aethiopicum Jakubz. were marked because they possess the most stable root system development indicators and a relatively high photosynthetic activity under stress.

Conclusions: The results of this research are very promising. They showed a variety of evolutionarily developed physiological mechanisms of protection from the effects of abiotic stresses. They allowed identifying the species as possessing the most stable indicators of growth and a relatively high photosynthetic activity under drought and salt stress. These species can be recommended as salinity and drought tolerance sources for interspecific crosses for different genetic programs.

\section{INTRODUCTION}

ccording to the UN (1), desert or drylands represent about half of

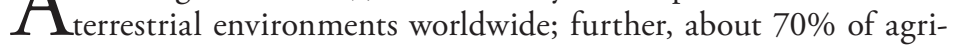
cultural land is affected by salinity. Thus, understanding how abiotic stressors, such as drought and salinity, affect plants is an urgent necessity. The continued growth of the human population necessitates increasing the area of crop production and enhancing productivity especially under stressful conditions. This goal requires en hanced research on vulnerability to stress the adaptive capacity of plants and improvement of the genetic potential for tolerance to abiotic stresses of crop varieties $(2-4)$. 
The productivity of agricultural plants is directly associated with their photosynthetic activity (PA) $(5,6)$. An integrated approach to the study of the physiological and biochemical bases of stress tolerance is impossible without attention to the function of the photosynthetic apparatus. This is because the preservation of photosynthetic activity under the influence of abiotic stressors largely determines their tolerance to adverse environmental factors ( 7 , 8). Because the mechanism of photosynthesis includes various components, e.g. photosynthetic pigments and photosystems, electron transport system and methods of reduction of $\mathrm{CO}_{2}$ level, any damage at each level caused by stress can reduce the photosynthetic ability of green plants (9).

The large body of previous research on the physiological processes in plants exposed to osmotic or saline stress has revealed that stress tolerance is associated with plant genomic composition, particularly with genes involved in photosynthesis (8). The introduction of the new species with great potential constitutive adaptability into the culture (the direction of a 'change of species') along with the genetic potential of cultivated species requires intensive research owing to the multiple unsuccessful attempts to increase stress tolerance, maturation rate and photosynthetic productivity of plants (10). Understanding how the different representatives of the tribe Triticeae experience drought stress and soil salinity is important for detecting new sources of drought and salt tolerance for the development of breeding and genetic research programs on important crops such has wheat (11).

This study aimed to identify growth reactions and associated changes in the photosynthetic apparatus of different species of wheat in response to drought and salinity in the environment.

We hypothesised that wheat species of different origins, ploidy level and genome composition may have different evolutionary mechanisms for the development of tolerance to abiotic stresses. Furthermore, stress tolerant varieties should exhibit fewer changes in growth rate and photosynthetic apparatus under stress conditions.

\section{MATERIALS AND METHODS}

Seven species of wheat, which are adapted to the conditions of southeast Kazakhstan, from the Institute of Plant Biology and Biotechnology collection were studied:

T. monococcum $\mathrm{L}$. $\left(\mathrm{A}^{\mathrm{u}} \mathrm{A}^{\mathrm{u}}\right)$ is associated with mountainous (but not high-mountain) areas. It was common in the Early Neolithic period. Currently, it occurs sporadically in Yugoslavia, Albania, Switzerland, Turkey and Morocco. NI Vavilov called the T. monococcum 'integrated battery immunity'.

T. dicoccum Schuebl. var. atratum (Host) Koern $\left(\mathrm{A}^{\mathrm{u}} \mathrm{A}^{\mathrm{u}} \mathrm{BB}\right)$ is distinctly polymorphic and differentiated among eco-geographical groups. It is tolerant to different climatic conditions and cultivated widely. Further, it ripens early and is unpretentious to the soil conditions, tolerant to diseases.

T. polonicum $\mathrm{L}$. var. villosum ( $\mathrm{A}^{\mathrm{u}} \mathrm{A} \mathrm{\textrm {B }} \mathrm{B}$ ) is an early ripening subspecies with a large grain and is found as an invasive in the steppe habitats of durum wheat in the Mediterranean, Ethiopia, Syria, Turkey, Iran, Afghanistan, the Caucasus and China.

T. aethiopicum Jakubz. (T. abyssinicum Vav.) ( $\left.\mathrm{A}^{\mathrm{u}} \mathrm{A}^{\mathrm{u}} \mathrm{BB}\right)$ belongs to a group growing in alpine steppes with humid and warm climates. It is cultivated in Ethiopia and Yemen on non-irrigated lands, where annual mean rainfall is about $1000 \mathrm{~mm}$ and large amount of it is accounted for by the first period of wheat vegetation.

T. compactum Host. ( $\left.\mathrm{A}^{\mathrm{u}} \mathrm{A}^{\mathrm{u}} \mathrm{BBDD}\right)$ is a relict species, which was previously widespread. It is cultivated sparsely in Turkey, Iran, China and Afghanistan. It is typically a mountainous polymorphic wheat species. In addition, it is similar to T. aestivum in a number of morphological characters. There is ongoing debate about its origin.

T. macha ssp. Densiusculum Dekapr. et. Menabde $\left(\mathrm{A}^{\mathrm{u}} \mathrm{A}^{\mathrm{u}} \mathrm{BBDD}\right)$ is the most ancient form of scarious hexaploid wheat. It is endemic to Georgia. It is not currently cultivated. It is associated with the forest belt from 300

Table 1. Relative growth of the first leaf and roots of seedlings of different wheat species under drought conditions (17.6\% sucrose, 72 h). Means \pm standard deviations are presented.

\begin{tabular}{|c|c|c|c|c|}
\hline \multirow{2}{*}{ Species } & \multicolumn{2}{|c|}{ Length, $\%$ of control } & \multicolumn{2}{|c|}{$\begin{array}{c}\text { Ratio } \\
\text { root / leaf, \% }\end{array}$} \\
\hline & leaf & root & control & stress \\
\hline T. monococcum & $80.9 \pm 4.5^{*}$ & $89.5 \pm 2.3^{*}$ & $56.3 \pm 3.0$ & $62.3 \pm 3.1$ \\
\hline T. dicoccum & $82.8 \pm 6.4^{*}$ & $93.6 \pm 2.5$ & $41.6 \pm 2.4$ & $47.0 \pm 2.3$ \\
\hline T. polonicum & $87.8 \pm 4.0^{*}$ & $127.2 \pm 3.0^{* *}$ & $43.7 \pm 1.9$ & $63.3 \pm 3.2^{* *}$ \\
\hline T. aethiopicum & $85.5 \pm 4.2^{*}$ & $92.6 \pm 2.5$ & $34.3 \pm 2.0$ & $31.7 \pm 2.0$ \\
\hline T. compactum & $76.7 \pm 2.7^{* *}$ & $157.9 \pm 3.8^{* *}$ & $35.9 \pm 1.9$ & $73.9 \pm 3.9^{* *}$ \\
\hline T. aestivum & $56.0 \pm 2.2^{* *}$ & $78.3 \pm 2.0^{* *}$ & $38.9 \pm 2.0$ & $54.5 \pm 3.5^{* *}$ \\
\hline
\end{tabular}

Note: ${ }^{*}{ }^{* *}$ indicate significant differences at $\mathrm{p} \leq 0.05$ and $\mathrm{p} \leq 0.01$ respectively 
to $1000 \mathrm{~m}$ above sea level in areas of high moisture. $T$. Macha may be a relict species of primarily hexaploid wheat.

T. aestivum L. (A $\left.{ }^{\mathrm{u}} \mathrm{A}^{\mathrm{u} B B D D}\right)$, Saratovskaya-29 is a soft wheat cultivar. Saratovskaya-29 is cultivated in many types of environments. It has a large ecological plasticity.

Seeds of the species of wheat studied were germinated in a growth chamber at $25^{\circ} \mathrm{C}$. After 48 hours, seedlings were transferred to $0.5 \mathrm{~L}$ pots and were grown for 5 days in water culture. Then for $72 \mathrm{~h}$, they were exposed to drought stress $(17.6 \%$ sucrose solution) or salt stress (1.68\% $\mathrm{NaCl}$ solution). These concentrations of sucrose and $\mathrm{NaCl}$ produced visual differences in samples in growth and biomass accumulation, when the growth of less stable seedlings reached $40-50 \%$ of control values $(12,13)$. Control seedlings were grown in water. These extreme treatments are often designated as 'shock' treatments (14); however, we used the traditional term 'stress', as defined by Selye as a state of the body formed in response to exposure to stress (15).

Chlorophyll was extracted in 96\% ethanol using purified glass sand to homogenise the samples. After centrifugation at $4^{\circ} \mathrm{C}$ (at 14,000 rpm), the chlorophyll $a$ and $b$ concentrations were determined with a spectrophotometer at $665 \mathrm{~nm}$ and $649 \mathrm{~nm}$, respectively, with a Genesis 10 UV Scanning (ThermoScientific, USA). The concentrations were calculated according to Lichtenthaler(16).

The Photosystem II (PSII) quantum yield and electron transport rate (ETR) were determined by recording the 'light curves' using a Chlorophyll Fluorometer IMAGING-PAM M ('Heinz WalzGmbH', Germany) under actinic illumination of $450 \mathrm{~nm}$. The fluorescent seedling leaf areas were out lined with the ImagingWin v.2.41a programme. At the beginning of each measurement, the leaf was exposed to light pulses at a frequency of $2 \mathrm{~Hz}$ for determination of $\mathrm{F}_{\mathrm{o}}$ (minimum fluorescence in the darkadapted state). Saturating pulses were applied to determine $\mathrm{F}_{\mathrm{m}}$ (maximum fluorescence in the dark-adapted state). The maximum quantum yield of PSII photochemistry $\left(\mathrm{F}_{\mathrm{v}} / \mathrm{F}_{\mathrm{m}}\right)$ was determined as $\left(\mathrm{F}_{\mathrm{m}}-\mathrm{F}_{\mathrm{o}}\right) / \mathrm{F}_{\mathrm{m}}$. Light curves were used for calculation of various fluorescence parameters at photosynthetic photon flux density (PPFD) of $0,1,21,56,111,186,281,336,396,461,531,611$ and $701 \mu \mathrm{mol}$ photons $/ \mathrm{m}^{2} \mathrm{~s}$. At the end of each illumination step, a saturating light pulse was applied for assessment of $\mathrm{F}_{\mathrm{m}}^{\prime}$ (maximum fluorescence yield in the light) and $\mathrm{F}_{\mathrm{s}}$ (steady state chlorophyll fluorescence yield in the light). The quantum efficiency of PSII photochemistry estimates the efficiency at which light absorbed by PSII is used for photochemistry and was calculated as $\left(\mathrm{F}_{\mathrm{m}}^{\prime}-\mathrm{F}_{\mathrm{s}}\right) / \mathrm{F}_{\mathrm{m}}^{\prime}(17)$. The value of $\mathrm{F}^{\prime}$ owas estimated using the approximation of Oxborough and Baker (1997), $\mathrm{F}_{\mathrm{o}}^{\prime}=\mathrm{F}_{\mathrm{o}} /\left(\mathrm{F}_{\mathrm{v}} / \mathrm{F}_{\mathrm{m}}+\mathrm{F}_{\mathrm{o}} /\right.$ $\left.\mathrm{F}_{\mathrm{m}}^{\prime}\right)$. The coefficient of photochemical quenching, $\mathrm{q}_{\mathrm{L}}$, which measures the fraction of PSII centres in the open state based on a lake model for the PSII photosynthetic apparatus, was estimated as $\left(\mathrm{F}_{\mathrm{m}}^{\prime}-\mathrm{F}_{\mathrm{s}} / \mathrm{F}_{\mathrm{m}}^{\prime}-\mathrm{F}_{\mathrm{o}}^{\prime}\right)\left(\mathrm{F}_{\mathrm{o}}^{\prime} / \mathrm{F}_{\mathrm{s}}\right)$ (18). The NPQ parameter, which was calculated as $\left(\mathrm{F}_{\mathrm{m}}\right.$ $\left.-\mathrm{F}_{\mathrm{m}}^{\prime}\right) / \mathrm{F}_{\mathrm{m}}^{\prime}$, estimates the non-photochemical quenching that reflects heat dissipation of excitation energy in the antenna system (19). Subsequent to illumination, the utilisation of absorbed photons by the PSII antennae in photosynthetic electron transport and thermal dissipation was assessed from the quantum efficiency (Y) of photochemical energy dissipation (Y(II)) andlight-dependent $(\mathrm{Y}(\mathrm{NPQ})$ and light-independent $(\mathrm{Y}(\mathrm{NO})$ thermal dissipation, with $\mathrm{Y}(\mathrm{II})+\mathrm{Y}(\mathrm{NPQ})+\mathrm{Y}(\mathrm{NO})=1$ (18). The quantum yield for dissipation through down-regulation in PSII (Y(NPQ)) was calculated from the equation $\mathrm{Y}(\mathrm{NPQ})=1-\mathrm{Y}(\mathrm{II})-1 /\left[\mathrm{NPQ}+1+\mathrm{q}_{\mathrm{L}}\left(\mathrm{F}_{\mathrm{m}} / \mathrm{F}_{\mathrm{o}}-1\right)\right]$ (18). The quantum yield of non-regulated energy dissipated in PSII, $\mathrm{Y}(\mathrm{NO})$, was calculated as $1 /\left[\mathrm{NPQ}+1+\mathrm{q}_{\mathrm{L}}\left(\mathrm{F}_{\mathrm{m}}\right.\right.$ / $\left.\left.\mathrm{F}_{0}-1\right)\right]$ (18). The relative PSII electron transport rate $($ ETR) was calculated as $\mathrm{c} \times \mathrm{Y}(\mathrm{II}) \times \mathrm{PPFD} \times 0.5$. For the coefficient $\mathrm{c}$, which estimates the absorption of PPFD by PSII, a value of 0.83 was assumed. The factor 0.5 takes into account that only half of the absorbed quanta is distributed to PS II (under steady state conditions). Each point in the light curves represents the averaged value of 12 leaf samples per treatment. ImagingWin v2.41a (Walz) software was used for calculating all parameters.

All leaf blades were examined microscopically at $10 \times$ magnification (Micros; Austria), photographed with a video camera (YONGXIN OPTICS CAM V200) and analysed with a computer program (YONGXIN OPTICS Scope Photo version 2.4).

Abnormal data were eliminated using t-criteria. Standard errors were calculated for all means.

All experiments were performed in triplicate. At least 25 plants were used in each replicate. The middle third of the leaf blades was harvested for chlorophyll content and determination of the photosynthetic parameters. All data were analysed using one-way analysis of variance (ANO$\mathrm{VA}$ ), with species and treatments as the main effects.

\section{RESULTS}

Examination of the impact of drought and salt stress on the growth characteristics of seedlings of six different wheat species revealed significant species-specific differences in the reduction of growth of the first leaf and roots (Tables 1 and 2).

Correspondingly, the root / leaf linear sizes relation decreased under saline conditions, which was most evident in T. compactum seedlings. Thus, sucrose-induced drought suppressed the growth of the first leaf more than root growth of the six different wheat species seedlings. Salt stress had a large influence on growth of the primary root of the studied species. The toxicity of salinity of growing environment caused the effect of 'avoidance' in roots (reduction in surface interaction with salt). The de- 
Table 2. Relative growth of the first leaf and the root of seedlings of different wheat species under salt stress $(1.68 \% \mathrm{NaCl}, 72 \mathrm{~h})$

\begin{tabular}{|c|c|c|c|c|}
\hline \multirow{2}{*}{ Species } & \multicolumn{2}{|c|}{ Length, $\%$ of control } & \multicolumn{2}{|c|}{$\begin{array}{c}\text { Ratio } \\
\text { root / leaf, \% }\end{array}$} \\
\hline & leaf & root & control & stress \\
\hline T. monococcum & $92.8 \pm 6.4$ & $78.0 \pm 5.1^{* *}$ & $30.9 \pm 3.5$ & $25.7 \pm 3.2$ \\
\hline T. dicoccum & $85.0 \pm 6.0^{*}$ & $100.0 \pm 3.2$ & $28.0 \pm 4.1$ & $33.3 \pm 5.1$ \\
\hline T. polonicum & $75.0 \pm 4.2^{* *}$ & $62.3 \pm 6.7^{* *}$ & $51.4 \pm 4.6$ & $41.5 \pm 3.8$ \\
\hline T. aethiopicum & $59.4 \pm 3.5^{* *}$ & $54.9 \pm 4.4^{* *}$ & $37.9 \pm 4.5$ & $35.2 \pm 4.8$ \\
\hline T. compactum & $80.9 \pm 6.4^{*}$ & $62.1 \pm 5.4^{* *}$ & $63.0 \pm 5.4$ & $48.8 \pm 4.3^{* *}$ \\
\hline T. aestivum & $60.8 \pm 6.9^{* *}$ & $58.6 \pm 4.6^{* *}$ & $44.8 \pm 4.3$ & $37.5 \pm 4.5$ \\
\hline
\end{tabular}

Note: ${ }^{*}{ }^{* *}$ indicate significant differences at $\mathrm{p} \leq 0.05$ and $\mathrm{p} \leq 0.01$ respectively
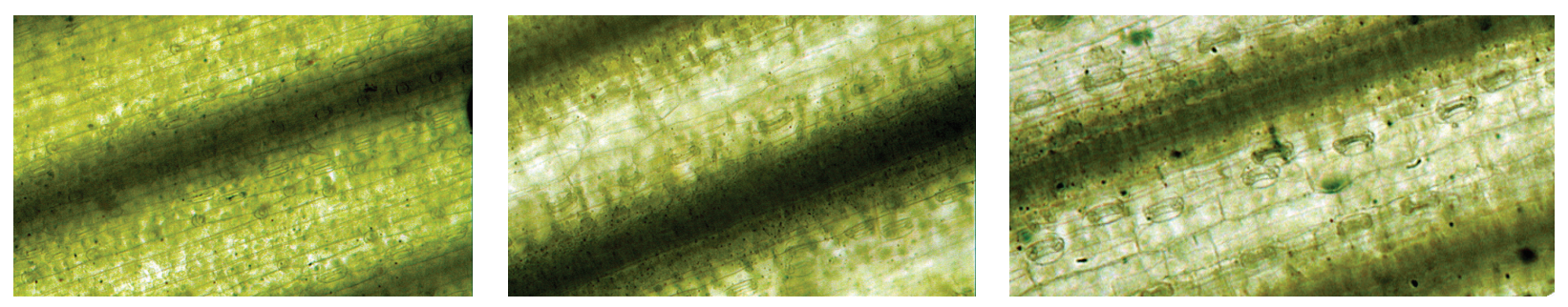

$a$-control, b-drought (17.6\% sucrose, 72 h), c-salinity ( $N a C l, 1.68 \%, 72$ h)

Figure 1. Colouring of leaf blades of $\mathrm{T}$. monococcum seedlings, magnification $10 \times$.

crease in the surface area of the leaves was a response to drought.

The relationship of root / leaf linear sizes (an important indicator of stress) of different wheat species also increased under drought conditions. T. polonicum, T. aestivum and T. compactum had the greatest increase in this ratio.

The root / leaf relationship for T. dicoccum and T. aethiopicum remained virtually unchanged under stress. The
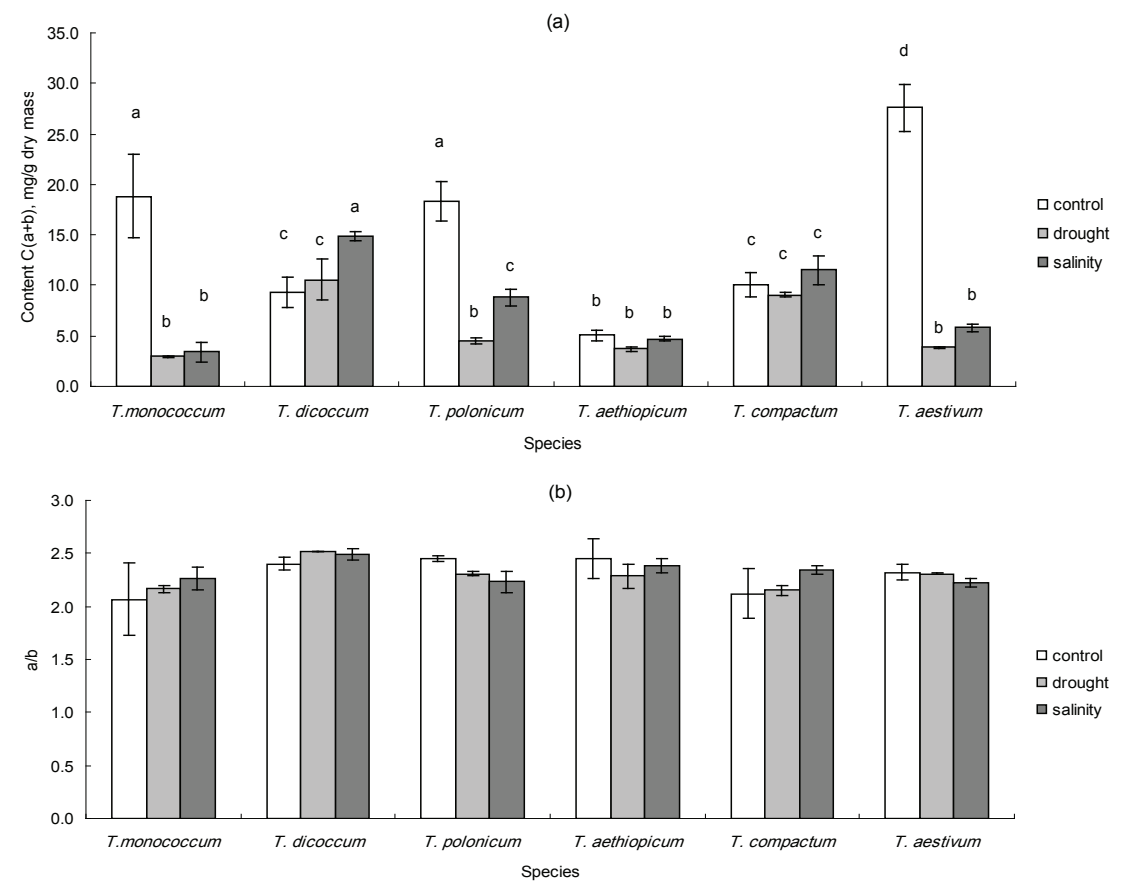

Figure 2. Concentrations of chlorophyll $(a+b)(a)$ and the ratio of chlorophyll a to chlorophyll $b(a / b)(b)$ in the leaves of six wheat species under drought and salinity conditions (17.6\% sucrose, $1.68 \% \mathrm{NaCl}, 72 \mathrm{~h})$. Values presented are means $( \pm \mathrm{SD})$. Different letters above the bars represent significant differences at $p \leq 0.05$. 
root/leaf relationship for seedlings of T. aestivum, T. aethiopicum, T. dicoccum and T. monococcum remained unchanged or slightly increased under salt stress.

These results indicate that the deceleration of leaf growth was greater than that for root growth and demonstrate the important role of actively functioning root systems of these species under stressful conditions.

Observations on leaf blades of different wheat species showed that the chromaticity of leaf blades of all studied species decreased under stress conditions, to a greater extent under salt stress than under drought (Fig. 1).

We observed a more uniform distribution of chloroplasts in the cells of the leaf blade in the absence of stress. Chloroplasts were concentrated in the areas of vascular bundles under stressful conditions. T. monococcum and $T$. aestivum seedlings had yellowing and necrotic sections of leaf blades under drought and T. polonicum had the same condition under salt stress.

T. aestivum had the highest concentration of chlorophyll $(a+b)$ in leaf blades $(27.57 \pm 2.30 \mathrm{mg} / \mathrm{g}$ dry mass $)$ under normal conditions (control). T. monococcum and T. polonicum had similar concentrations of chlorophyll $(a+b)(18.83$ \pm 4.17 and $18.36 \pm 1.95 \mathrm{mg} / \mathrm{g}$, respectively), as well as $T$. dicoccum and T. compactum $(9.34 \pm 1.48$ and $10.09 \pm 1.22$ $\mathrm{mg} / \mathrm{g}$ dry mass, respectively). T. aethiopicum had the lowest chlorophyll content $(5.07 \pm 0.5 \mathrm{mg} / \mathrm{g}$ dry mass) (Fig. 2a).

Thus, the chlorophyll content in leaf blades was species-specific in the absence of stress, but it was independent of the ploidy level of the species studied.

The chlorophyll content of all studied species decreased significantly (by $75 \%$ - 84\%) under stressful conditions except for T. dicoccum, T. compactum and T. aethiopicum, which had values that were almost unchanged or even increased ( $T$. dicoccum). Furthermore, the chlorophyll content in leaves of almost all studied species was higher under salt stress than under drought stress.

The 'saturation pulse' method was used for the detection of the effects of drought and salinity stress on wheat leaves of different species. For non-stressed C3 plants, values of about 0.83 (20) are expected. These approximate values were obtained in the analysis of experiments conducted here with control groups of the species. Susceptibility to photo inhibition in drought and salinity-stressed wheat leaves in our study was determined as changes in the $\mathrm{F}_{\mathrm{v}} / \mathrm{F}_{\mathrm{m}}$ ratio (Table 3). These values decreased (with one exception T. compactum under salinity) under stress conditions.

Therefore, analysis of 'light curves' show that T. monococcum and $T$. aethiopicum maintained high photosynthetic activity (PA) (the curve is very similar to the control ETR curve) under stress conditions. Other investigated species decreased their PA notably under stress influence in this experiment; reaction centres of PSII of most species closed by PPFD of $460 \mu \mathrm{mol} / \mathrm{m}^{2} \mathrm{~s}$ (Fig.3).

As shown in Fig.4, most species had higher Y(NPQ) under induced drought than in controls. As has been de- scribed in Arabidopsis, a plant can protect itself from shortterm exposure to stressful conditions through increasing non-photochemical components (21). However, the PA reaction to drought and salinity differed from species to species. Only leaves of $T$. dicoccum showed a sharp decrease of Y(NPQ) at PPFD of $395 \mu \mathrm{mol} / \mathrm{m}^{2} \mathrm{~s}$, when the level of non regulated dissipation $(\mathrm{Y}(\mathrm{NO})$ increase date PPFD $460 \mu \mathrm{mol} / \mathrm{m}^{2} \mathrm{~s}$. These parameters were similar to control levels before this change (Figs. $4 \mathrm{~b}$ and $5 \mathrm{~b}$ ). High values of $\mathrm{Y}(\mathrm{NO})$ may be indicative of serious problems in dealing with incident radiation experienced by the plant. Thus, there likely was some damage to the functioning of PSII or even to its structure (22).

T. monococcum seedling leaves had the maximum PA decrease under salinity conditions. In addition, the nonregulated energy dissipation of this variety significantly increased (Fig. 4). As stated previously, such changes can indicate serious damage to the functioning of PSII.

T. aethiopicum, T. dicoccum and the hexaploid species T. compactum appeared to be the most tolerant to salt stress. They had levels of Y(NPQ) similar to the controls, as shown in Fig. 4. Furthermore, there were no significant differences in the $\mathrm{F}_{\mathrm{v}} / \mathrm{F}_{\mathrm{m}}$ ratio (Table 3)
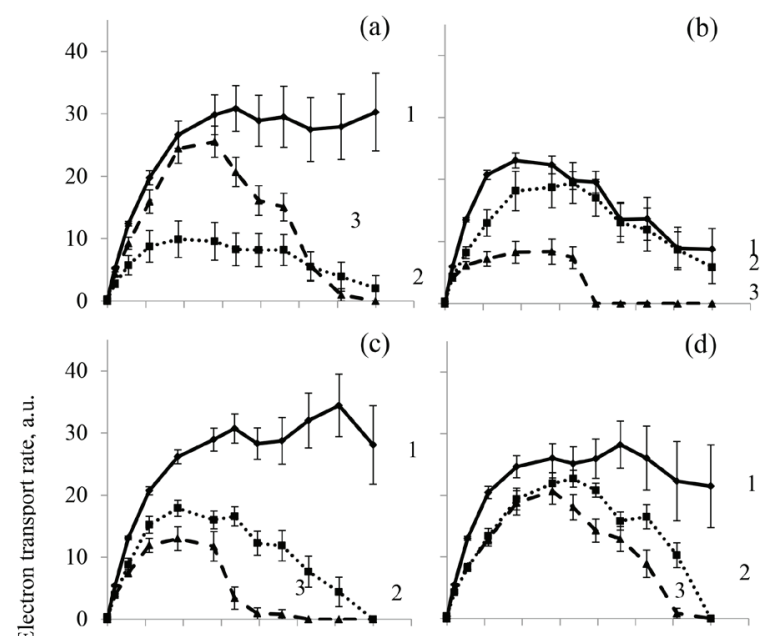

(d)

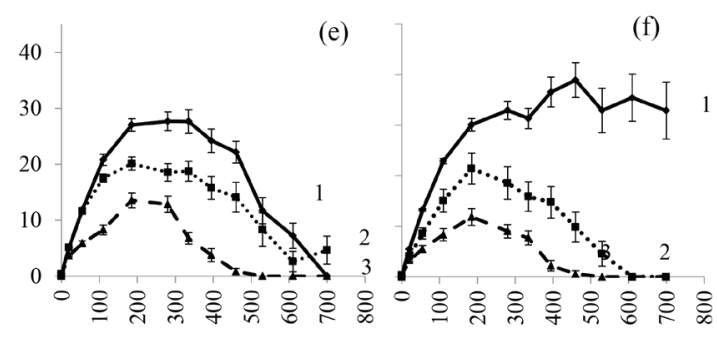

Photosynthetic photon flux density, $\mu \mathrm{mol} / \mathrm{m}^{2} \mathrm{~s}$

Figure 3. ETR changes of 10-day-old wheat seedlings: (a) T. monococcum, (b) T. dicoccum, (c) T. polonicum, (d) T. aethiopicum, (e) T. compactum and $(f)$ T. aestivum under different conditions: 1 -control, 2-salinity, 3-drought. Data presented are means \pm standard error. 


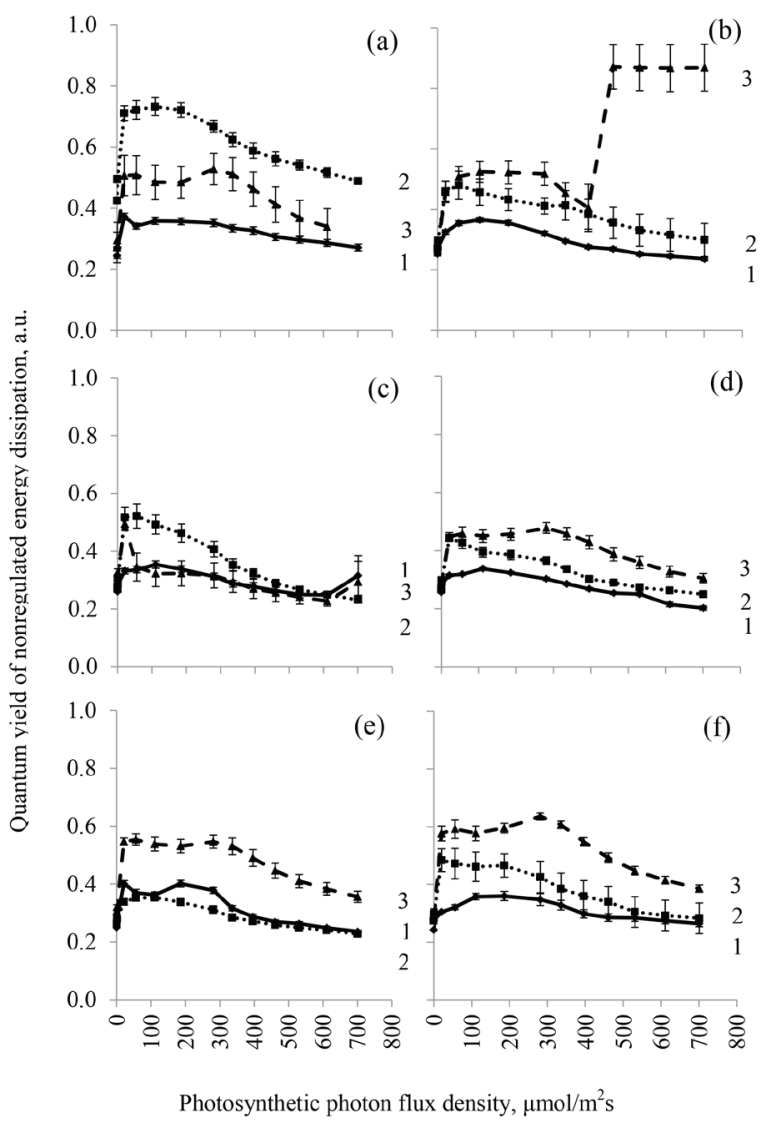

Figure 4. The $Y(N O)$ change of 10-days wheat seedlings: (a) $\mathrm{T}$. monococcum, (b) T. dicoccum, (c) T. polonicum, (d) T. aethiopicum, (e) T. compactum and $(f) \mathrm{T}$. aestivum under different conditions: 1 -control, 2 - salinity, 3 -drought. Data presented are means \pm standard error.

Leaves of these species compensated for the oversupply of irradiation mostly through a regulated dissipation mechanism, so the influence of salinity on their leaf PSII was slight. The retention of chlorophyll quantity of these species at the same level as the control under salt stress, opposite to the finding for drought conditions (Fig. 2), also confirms their photosynthetic apparatus is less vulnerable to salt stress.

Finally, the decrease of ETR under stress conditions was detected during this investigation of drought and salinity influence on PA of soft wheat and leaves of its wild congeners. However, the analysis of other PA components revealed that some tolerant species could be distinguished, T. monococcum L. and T. aethiopicum to drought and T. aethiopicum, T. dicoccum, T. compactum and T. polonicum to salinity, which may possess dynamic tolerance to drought according to their high level of Y(NPQ).

\section{DISCUSSION}

Economic losses of crops are greater if plants are subjected to stress at the juvenile stage of development. Therefore, the ability of plants to efficiently use water under drought at the early stages of their development is an important agronomic character; the growth response of seedlings to stressful conditions is a visual indicator of metabolism changes (23).

The strong negative effects of salt stress on the root systems of seedlings and drought stress on leaf composition juvenile plants of different wheat species were revealed. The effect of induced osmotic stress (at the drought stage or the osmotic component of salt stress) on plants occurs immediately when the solutions / stressors contact the root system. The plants usually achieve osmotic homeostasis relatively quickly at non critical concentrations of the stressor. However, salt stress begins to have toxic effects including changes in the ion balance and a critical concentration of $\mathrm{Na}^{+}$in the cytoplasm $(14,24)$. Concurrently, different species, regardless of their level of drought and salt tolerance, vary in the degree of plasmolysis of cells and normal cellular activities may be restored $(14,25)$. However, the most complete characterisation of stability I sensitivity of the species studied only provide a complex assessment of various parameters of the leaf blades and root system.

Our experimental data revealed that the tetraploid species $T$. dicoccum had the most stable indicators of development of seedling root systems under drought and salt stress and that T. aethiopicum had good indicators of seedlings under drought stress.

Often under stressful conditions, the regulation of water absorption by roots is more important for overcoming the severe impacts of stress than the regulation of transpiration and photosynthesis in leaves (26). However, the

Table 3. Mean PSII $F_{v} / F_{m}$ of different wheat species seedlings under drought (17.6\% sucrose, 72 h) and salinity (NaCl, 1.68\%, 72 h) conditions (means \pm standard deviations).

\begin{tabular}{|lccc|}
\hline Species & control & drought & salinity \\
\hline T. monococcum & $0.76 \pm 0.01$ & $0.73 \pm 0.03^{* *}$ & $0.58 \pm 0.10^{* *}$ \\
T. dicoccum & $0.75 \pm 0.01$ & $0.71 \pm 0.03^{* *}$ & $0.73 \pm 0.03^{*}$ \\
T. polonicum & $0.74 \pm 0.01$ & $0.70 \pm 0.04^{* *}$ & $0.73 \pm 0.01^{* *}$ \\
T. aethiopicum & $0.74 \pm 0.01$ & $0.72 \pm 0.01^{* *}$ & $0.73 \pm 0.01^{* *}$ \\
T. compactum & $0.75 \pm 0.02$ & $0.70 \pm 0.03^{* *}$ & $0.74 \pm 0.01$ \\
T. aestivum & $0.76 \pm 0.00$ & $0.71 \pm 0.02^{* *}$ & $0.73 \pm 0.04^{*}$ \\
\hline
\end{tabular}

Note: ${ }^{*}{ }^{* *}$ indicate significant differences at $\mathrm{p} \leq 0.05$ and $\mathrm{p} \leq 0.01$ respectively 
changing dynamics in photosynthetic activity of plant leaves under stress reflect the degree of influence of the stress on the above ground part of the plant as well as the coherence of the entire plant body.

The total pigment content and their relative ratios in any plant species are not constant. They may vary considerably depending on factors such as the structural features of the leaf blades, environmental growth conditions and human activity (27). Owing to the destruction of chlorophyll, the photosynthetic activity in plants cultivated under stressful conditions may be reduced. However, the correlation between pigment concentration in a plant's leaves and its stress tolerance is not always evident according to Fang et al. (28) and Khan et al. (29). Data on chlorophyll content are contradictor; both accumulation of chlorophyll under stress conditions $(30,31)$ and a significant decrease in chlorophyll have been observed, especially in stress sensitive varieties for both dicotyledonous and monocotyledonous species $(4,32,33)$. Changes in chlorophyll content of leaves under stress may be associated with accelerated degradation of the pigment or with disruption of its biosynthesis. In addition, previous studies indicated that in the process of degradation, chlorophyll $b$ can be converted to chlorophyll $a$ resulting in increased chlorophyll content $(34,35)$. Furthermore, a series of experiments on sunflower (32) determined that stress affects the process of chlorophyll biosynthesis rather than decreasing chlorophyll concentration.

Previous studies revealed that chlorophyll $b$, as the main component of the photosystems, is damaged more than chlorophyll $a$ under stress (36). In general, species with a lower ratio of chlorophyll $a / b$ show a greater adaptability to environmental conditions. There is evidence that reduction in the ratio of chlorophyll $a / b$ is correlated with an increase in productivity (37). However, in our experiments, the ratio of chlorophyll $a / b$ was stable, independent of the changes in total chlorophyll content, suggesting that the osmotic and salt stresses applied in this study did not cause significant structural changes in the photosynthetic apparatus of seedlings of different wheat species.

Stress can lead to a decrease in the efficiency of the light-absorbing ability of leaves owing to disruption of photosystems I and II (PSI and PSII) $(38,39)$. The fluorescence of chlorophyll is considered to be an important indicator of stress tolerance in different species and varieties of plants, for example, durum, wheat and tobacco (40, $41,42) . \mathrm{F}_{\mathrm{v}} / \mathrm{F}_{\mathrm{m}}$ are considered to be a fast-measuring indicator of stress in plants. Guretzki and Papenbrock (43) found no significant differences in $\mathrm{F}_{\mathrm{v}} / \mathrm{F}_{\mathrm{m}}$ between control and drought groups of L. purpureus under mild stress. This result is consistent with other studies $(44,45)$. However, all of these studies were conducted on adult plants. Our work with seedlings supports the utility of this parameter, in addition to other fluorescence measurements in stress tolerance screenings.
'Light curves' can provide some information about changes that occur in PSII performance under different conditions. The ETR curves are very close in shape to a photosynthesis-irradiance curve. With low irradiance, photosynthesis is limited by the irradiance. The slope of the curve in the light limiting region is proportional to the efficiency of light capture (effective quantum yield). Under moderate irradiance, the capacity of the electron transport chain limits photosynthesis and the curve reaches a plateau, where the maximum photosynthetic capacity occurs. With even higher irradiance (supra-saturating), the curve often tends to decline (46). However, this decline could be linked to dynamic down-regulation of PSII (47), maximum ETR displays a level of PA in this case (48). The changes in the level of maximum ETR and the PPFD at which the plateau is reached are supposed to display the level of variety stress tolerance.

Different wheat species may have evolved a variety of physiological mechanisms for protection against the influences of abiotic stress. The results presented here revealed that seedling leaf blades of $T$. aethiopicum, which had a slight decrease in growth functions, maintained a similar ratio of chlorophyll $a$ / $b$ as the control on the background
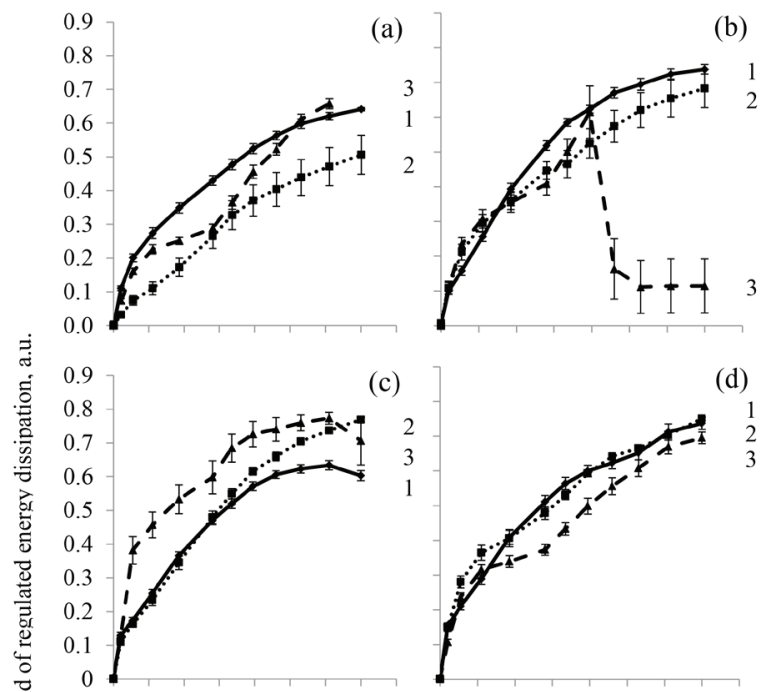

(d)
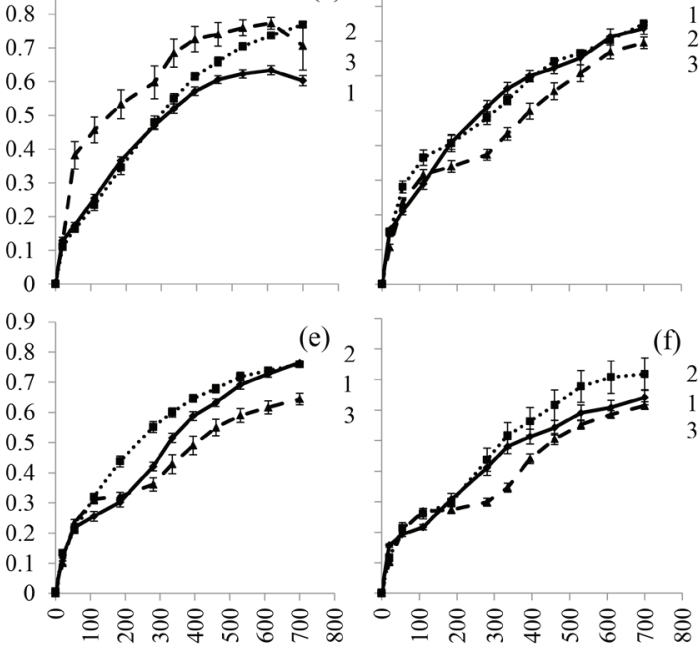

Photosynthetic photon flux density, $\mu \mathrm{mol} / \mathrm{m}^{2} \mathrm{~s}$

Figure 5. The $Y(N P Q)$ change of 10-days wheat seedlings: (a) $\mathrm{T}$. monococcum, (b) T. dicoccum, (c) T. polonicum, (d) T. aethiopicum, (e) T. compactum and $(f) \mathrm{T}$. aestivum under different conditions: 1 -control, 2 - salinity, 3 -drought. Data presented are means \pm standard error. 
of minimum reducing the total chlorophyll content and also showed a high photosynthetic activity. Interestingly, the seedling leaves of the tetraploid species $T$. polonicum increased inefficiency of non-photochemical quenching of fluorescence despite a decline in the PA, indicating that the functioning of PSII is damaged under drought conditions. This finding may demonstrate the dynamic drought tolerance of this species; when the plant is dehydrated, complex protective responses and adaptive reactions may occur, some of which are specific to this species (49). The effects of different genomes have been observed in ecological and genetic studies on wheat (50). These data provide substantial information on the role of the genome in the evolution of the physiological and genetic mechanisms of drought and salt tolerance in wheat species.

\section{CONCLUSION}

Our experiments revealed a number of common mechanisms that regulate growth and photosynthetic activity of the leaf apparatus of seedlings of different wheat species seedlings under abiotic stresses such as drought and salinity. Furthermore, species-specific differences in the response to induced drought and salt stress were demonstrated.

Salt stress was shown to have a greater negative effect on the root system of seedlings of different species of wheat than drought, while drought stress had a greater effect on the leaf apparatus of juvenile plants.

Among the wheat species with different origins, levels of ploidy and genomic composition, a variety of evolutionary mechanisms for protection against exposure to stressors in the form of tolerance were identified in species such as the tetraploid species T. dicoccum and T. aethiopicum. Seedlings of these species have less decrease in growth and fewer changes in the photosynthetic apparatus under abiotic stress conditions. In addition, they have the most stable indicators of root system development in seedlings and relatively high photosynthetic activity of leaves under drought and salt stress. The tetraploid species T. dicoccum and T. aethiopicum can be utilised as sources of salinity and drought tolerance for interspecific crosses for breeding and genetic programs.

Acknowlements: research carried out in the framework of the project 1104/GF4 'Study of stability of photosynthetic apparatus of wheat (T. aestivum $L$.) and its wild congeners to abiotic stress in vivo and in vitro'. This grant are funding by the Ministry of Education and Science of the Republic of Kazakhstan.

The authors would like to thank Enago (www.enago.com) for the English language review.

\section{REFERENCES}

1. Climate and disaster resilience / United Nations Development Programme. 2015 http://www.undp.org/content/undp/en/home/ ourwork/climate-and-disaster-resilience/overview.html
2. GUPTA R I 2009 A view of researches on steady management of land resources in Central Asia. The IKARDA Program in Central Asia and Transcaucasia, a Series 1, KGMSHI-ORP: Tashkent Uzbekistan

3. EL-SHAFEY N M, RAIFA A H, MAHMOUD M A G, ELSHEIHY O 2009 Pre-exposure to gamma rays alleviates the harmful effect of drought on the embryo-derived rice calli. Aust. J Crop Sci 3(5): 268-277

4. MAFAKHERI A, SIOSEMARDEH A, BAHRAMNEJAD B, STRUIK P C, SOHRABI Y 2010 Effect of drought stress on yield, proline and chlorophyll contents in three chickpea cultivars. Aust J Crop Sci 4: 580-585

5. KNYAZEV B M, KHAMOKOV K A 2005 Photosynthetic activity and soybean productivity in conditions of insufficient humidifying. Grain economy 2: 17-18

6. MOHAMMADI M, KARIMIZADEH R A, NAGHAVI M R 2009 Selection of bread wheat genotypes against heat and drought tolerance based on chlorophyll content and stem reserves. Journal of Agriculture \& Social Science 5: 119-122

7. MUNNS R, JAMES R A, LÄUCHLI A 2006 Approaches to increasing the salt tolerance of wheat and other cereals. J Exp Bot 57(5): 1025-104. https://doi.org/10.1093/jxb/erj100

8. CHAVES M M, FLEXAS J, PINHEIRO C 2008 Photosynthesis under drought and salt stress: regulation mechanisms from whole plant to cell: Annals of Botany 103(4): 551-560

9. ASHRAF M, HARRIS P J C 2013 Photosynthesis under stressful environments: An overview. Photosynthetica 51(2): 163-190 https://doi.org/10.1007/s11099-013-0021-6

10. ZHUCHENKO A A 2004 Ecological genetics of cultivated plants and problems agrosphere (theory and practice). V.1. Moskow, Agrorus: $689 \mathrm{p}$

11. GUO RUI, WEI PING HAO, DAO ZHI GONG, XIU LI ZHONG, FENG XUE GU 2013 Effects of Water Stress on Germination and Growth of Wheat, Photosynthetic Efficiency and Accumulation of Metabolites: In "Soil Processes and Current Trends in Quality Assessment", book edited by Maria C. Hernandez Soriano http://www.intechopen.com/books

12. Diagnostics stability of plant resistance to stress 1988 Methodical guidance edited by Udovenko GV, Leningrad, VIR: 89 pp

13. TERLETSKAYA N V, SARIEV B S, ISKAKOV A R 1992 Round method of evaluating of drought resistance of barley: Almaty, KazRNKI 169: $10 \mathrm{p}$

14. SHAVRUKOV YU 2013 Salt stress or salt shock: which genes are we studying. J Exp Bot 64(1): 119-127 https://doi.org/10.1093/jxb/ers316

15. SELYE H 1972 At the level of the whole organism. Moskow Nauka, $122 \mathrm{p}$

16. GENTY B, BRIANTAIS J M, BAKER NR 1989 The relationship between the quantum yield of photosynthetic electron transport and quenching of chlorophyll fluorescence. Biochimica et Biophysica Acta 990: 87-92

17. KRAMER D M, JOHNSON G, KIIRATS O, EDWARDS G E 2004 New fluorescence parameters for the determination of QA redox state and excitation energy fluxes. Photosynthesis Research 79: 209-218

18. BILGER W, BJÖRKMAN O 1991 Temperature dependence of violaxanthin deep oxidation and non-photochemical fluorescence quenching in intact leaves of Gossypiumbirsutum L. and Malvaparviflora L. Planta 184: 226-234 https://doi.org/10.1007/BF01102422

19. BJÖRKMAN O, DEMMIG B 1987 Photon yield of O2 evolution and chlorophyll fluorescence characteristics at $77 \mathrm{~K}$ among vascular plants of diverse origins. Planta 170: 489-504 https://doi.org/10.1007/BF00402983 
20. GRAßES T, PESARESI P, SCHIAVON F, VAROTTO C, SLAMINI F, JAHNS P, LEISTER D 2002 The role of $\Delta \mathrm{pH}$ dependent dissipation of excitation energy in protecting photosystem II against light-induced damage in Arabidopsis thaliana. Plant Physiology and Biochemistry 40: 41-49

21. SPERDOULI I, MOUSTAKAS M 2012 Spatio-temporal heterogeneity in Arabidopsis thaliana leaves under drought stress. Plant Biology 14: 118-128

22. LICHTENTHALER H K 1987 Chlorophylls and carotenoids: Pigments of photosynthetic biomembranes. Method Enzymol 148: 350-382 https://doi.org/10.1016/0076-6879(87)48036-1

23. KOZHUSCKO N N 1991 The study of drought resistance of global gene pool of spring wheat for breeding purposes, Leningrad, VIR: $92 \mathrm{p}$

24. MUNNS R 2002 Comparative physiology of salt and water stress. Plant Cell and Environment 25: 239-250 https://doi.org/10.1046/j.0016-8025.2001.00808.x

25. TERLETSKAYA N V, KHAILENKO N A 2015 Osmotic stress effect on different cytological characters of roots and grown parameters in different wheat species. Annual Research \& Review in Biology 5: 347-356 https://doi.org/10.9734/ARRB/2015/11825

26. AROCA R, PORCEL R, RUIS-LOZANO J M 2011 Regulation of Root Water Uptake under Drought Stress Conditions. J Exp Bot 63(1): 43-57 https://doi.org/10.1093/jxb/err266

27. RONZHINA E S 2004 Structural and functional changes of mesophyll as a possible cause of cytokinin-dependent transport of substances in the leaves isolated. Plant Physiol 51 (3): 373-382

28. FANG Z, BOUWKAMPAND J, SOLOMOS T 1998 Chlorophyll ace activities and chlorophyll degradation during leaf senescencein non-yellowing mutant and wild type of Phaseolus vulgaris L. J Exp Bot 49: 503-510

29. KHAN M A, SHIRAZI M U, KHAN M A, MUJTABA S M, ISLAM E, MUMTAZ S, SHEREEN A, ANSARI R U, ASHRAF M Y 2009 Role of proline, K/Na ratio and chlorophyll content in salt tolerance of wheat (Triticum aestivum L.). Pak J Bot 41: 633638

30. ESTILL K, DELANEY R H, SMITH W K, DITTERLINE R L 1991 Water relations and productivity of alfalfa leaf chlorophyll variants. Crop Sci 31: 1229-1233 https://doi.org/10.2135/cropsci1991.0011183X003100050030x

31. PIRZAD A, SHAKIBA M R, ZEHTAB-SALMASI S, MOHAMMADI S A, DARVISHZADEH R, SAMADI A 2011 Effect of water stress on leaf relative water content, chlorophyll, proline and soluble carbohydrates in Matricaria chamomilla L. J. Medicinal Plants Res 5: 2483-2488

32. AKRAM N A, ASHRAF M 2011 Improvement in growth, chlorophyll pigments and photosynthetic performance in salt-stressed plants of sunflower (Helianthus annuus L.) by foliar application of 5-aminolevulinic acid. Agrochimica 55: 94-104

33. DIN J, KHAN S U, ALI I, GURMANI A R 2011 Physiological and agronomic response of canola varieties to drought stress. $J$ Anim Plant Sci 21: 78-82

34. SANTOS CV 2004 Regulation of chlorophyll biosynthesis and degradation by salt stress in sunflower leaves. Sci Hort 103: 93-99 https://doi.org/10.1016/j.scienta.2004.04.009

35. ECKARDT NA 2009 A new chlorophyll degradation pathway. Plant Cell 21: 700. https://doi.org/10.1105/tpc.109.210313

36. MAUCHAMP A, MÈTHY M 2004 Submergence-induced damage of photosynthetic apparatus in Phragmites australis. Environ
Exp Bot 51: 227-235

https://doi.org/10.1016/j.envexpbot.2003.11.002

37. FEDULOV YuP, PODUSHIN YuV 2009 The content and ratio of chlorophylls in winter wheat leaves, depending on the agrotechnical methods of its cultivation Scientific Journal of KubSAU 51 (7): $1-13$

38. HAVAUX M, ERNEZ M, LANNOYE R 1988 Correlation between heat tolerance and drought tolerance in cereals demonstrated by rapid chlorophyll fluorescence tests. J Plant Physiol 133: 555560 https://doi.org/10.1016/S0176-1617(88)80007-5

39. ZHANG L T, ZHANG Z S, GAJ H Y, XUE Z C, YANG C, MENG X L, MENG Q W 2011 Mitochondrial alternative oxidase pathway protects plants against photoinhibition by alleviating inhibition of the repair of photodamaged PSII through preventing formation of reactive oxygen species in Rumex K-1 leaves. Physiol Plant 143: 396-407

40. VAN RENSBURG L, KRÜGER G H J, EGGENBERG P, STRASSER R J 1996 Can screening criteria for drought resistance in Nicotiana tabacum L. be derived from the polyphasic rise of the chlorophyll a fluorescence transient (OJIP). S Afr J Bot 62: 337-341

41. ARAUS J L, AMARO T, VOLTAS J, NAKKOUL H, NACHIT M M 1998 Chlorophyll fluorescence as a selection criterion for grain yield in durum wheat under Mediterranean conditions. Field Crops Res 55: 209-223

42. LITVIN F F, BELYAEVA O B, IGNATOV N V 2000 Chlorophyll biosynthesis and formation of photochemical reaction centers of photosynthesis systems. Advances of Biological Chemistry 40: 3-432

43. GURETZKI S, PAPENBROCK J 2013 Comparative analysis of methods analyzing effects of drought on the herbaceous plant lab purpureus. Journal of Applied Botany and Food Quality 86: 47-54

44. WOO N S, BADGER M R, POGSON B J 2008 A rapid, noninvasive procedure for quantitative assessment of drought survival using chlorophyll fluorescence. Plant Methods 4: 1746-1760 https://doi.org/10.1186/1746-4811-4-27

45. MIYASHITA K, TANAKAMARU S, MAITANI T, KIMURA K 2005 Recovery responses of photosynthesis, transpiration, and stomatal conductance in kidney bean following drought stress. Environ. Exp. Bot 53: 205-214 https://doi.org/10.1016/j.envexpbot.2004.03.015

46. SCHREIBER U 2004 Pulse-amplitude (PAM) fluorometry and saturation pulse method: In Papageorgiou G, Govindjee, (Eds.), Chlorophyll fluorescence: A Signature of Photosynthesis. Advances in Photosynthesis andRespiration Series. Kluwer Academic Publishers, Dordrecht, The Netherlands.

47. WHITE A J, CRITCHLEY C 1999 Rapid light curves: a new fluorescence method to assess the state of the photosynthetic apparatus. Photosynth. Res 59: 63-72

48. RALPH P J, GADEMANN R 2005 Rapid light curves: A powerful tool to assess photosynthetic activity. Aquatic Botany 82: 222-237

49. GONCHAROVA E A, CHESNOKOV Yu V, SITNIKOV M N 2013 A retrospective review of research into the water status of cultivated plants based on the genetic resources collection of the all-russian research institute of plant industry. Proceedings of Karelian Research Centre of Russian Academy of Sciences 3: 10-17

50. CHESNOKOV Yu V, POCHEPNYA N V, BERNER A 2008 Environmental and genetic organization of quantitative trait loci mapping of plants and determining agronomically important traits in wheat. $D A N$ 418: 693-696 